Original Article Journal of Epilepsy Research pISSN 2233-6249 / eISSN 2233-6257

Received March 12, 2020

Revised April 9, 2020

Accepted May 4, 2020

Corresponding author:

Modibo Sangare, MD, PhD

Faculty of Medicine and Odontostomatology (FMOS), University of Sciences, Techniques $\&$ Technologies of Bamako (USTTB), Point G, Bamako BP 1805, Mali

Tel. +223-99 975556

Fax. +223-20 229658

E-mail; mouadib@gwu.edu

\section{Epilepsy Research in Mali: A Pilot Pharmacokinetics Study on First-Line Antiepileptic Drug Treatment}

\author{
Modibo Sangare, MD, PhD ${ }^{1,2}$, Fatoumata Doumbia, $\mathrm{MD}^{1}$, Oumar Sidibe, PharmD ${ }^{3}$,
} Aboucacar Alassane Oumar, PharmD, PhD ${ }^{3}$, Sekou Bah, PharmD, PhD ${ }^{3}$, Modibo Kouyate, $\mathrm{Msc}^{4}$, Seidina S. Diakite, PharmD, PhD ${ }^{1,3}$, Karim Traore, PharmD, PhD ${ }^{3}$, Adama Karembe, $\mathrm{MD}^{1}$, Mohamed S. Haidara, MD1, Souleymane P. Coulibaly, MD1, Souleymane Coulibaly, MD1, Arouna Togora, MD1, Housseini Dolo, MD, Msc' , Drissa Traore, MD'1, Seydou Doumbia, MD, $\mathrm{PhD}^{1}$, Mahamadou Diakite, PharmD, PhD ${ }^{3}$, Youssoufa Maiga, MD, Msc', Amadou Diawara, PharmD ${ }^{5}$, Callixte Kuate, $\mathrm{MD}^{6}$, Hyung-Goo Kim, $\mathrm{PhD}^{7}$, Gordon A. Awandare, PhD ${ }^{2}$

${ }^{1}$ Faculty of Medicine and Odontostomatology (FMOS), University of Sciences, Techniques \& Technologies of Bamako (USTTB), Bamako, Mali; ${ }^{2}$ West African Centre for Cell Biology of Infectious Pathogens (WACCBIP), University of Ghana, Accra, Ghana; ${ }^{3}$ Faculty of Pharmacy, University of Sciences, Techniques \& Technologies of Bamako (USTTB), Bamako; ${ }^{4}$ African Center of Excellence in Bio-informatics (ACE), University of Sciences, Techniques \& Technologies of Bamako (USTTB), Bamakom; ${ }^{5}$ Algi Biomedical Analysis Lab, Bamako, Mali; ${ }^{6}$ Central Neurology Hospital, Yaounde, Cameroun; ${ }^{7}$ Neurological Disorders Research Center, Qatar Biomedical Research Institute (QBRI), Doha, State of Qatar

Background and Purpose: The indication and benefit of plasma level of antiepileptic (AEDs) has been debating in the monitoring of people living with epilepsy and the epilepsy treatment gap has largely been documented in developed countries. This study was aimed to highlight the epilepsy treatment gap between rural and urban Mali.

Methods: We conducted a pilot study on AEDs treatment from September 2016 to May 2019. For 6 months, 120 children and young adults living with epilepsy (rural site, 90; urban site, 30) received phenobarbital, valproic acid and/or carbamazepine. At our rural study site, we determined the AED plasma levels, monitored the frequency, severity and the duration of seizure, and administered monthly the McGill quality of life questionnaire. At our urban study site, each patient underwent an electroencephalogram and brain computed tomography scan without close monitoring.

Results: At the rural study site, patients were mostly on monotherapy; AED levels at 1 month (M1) ( $n=90)$ and at 3 months (M3) ( $n=27)$ after inclusion were normal in $50 \%$ at $M 1$ versus $55.6 \%$ at $M 3$, low in $42.2 \%$ at $\mathrm{M} 1$ versus $33.3 \%$ at $\mathrm{M} 3$ and high in $7.8 \%$ at $\mathrm{M} 1$ versus $11.1 \%$ at $\mathrm{M} 3$. AED levels at $\mathrm{M} 1$ and at $\mathrm{M} 3$ were significantly different $p<0.0001$. By $M 3$, seizures $(n=90)$ were $<1 /$ month in $26.7 \%$, and lasted less than 1 minute in $16.7 \%$. After a yearlong follow up, all 90 patients reported a good or excellent quality of life. At our urban study site, patients $(n=30)$ were on carbamazepine and valproid acid in $66.67 \%$ and monotherapy (carbamazepine) in $33.33 \%$. By November 2018, only six out 30 patients (on bi-therapy) were still taking their medications.

Conclusions: Epilepsy diagnostic and treatment are a real concern in Mali. Our data showed appropriate AED treatment with close follow up resulted in a better quality of life of patients in rural Mali. We will promote the approach of personalized medicine in AED treatment in Mali. (2020;10:31-39)

Key words: Epilepsy, Carbamazepine, Quality of life, Phenobarbital, Valproic acid, Mali 


\section{Introduction}

In this pilot study, we addressed a relevant research question on epilepsy treatment gap in a developing country, Mali. Our findings highlighted the importance of the disparity between urban and rural Mali in the diagnostic and drug treatment of epilepsy. We proposed a sequential evaluation of the frequency, duration of seizure and quality of life of patients as a follow up tool of people living with epilepsy and antiepileptic drug (AED) treatment in rural Mali. Our data have been well discussed and put into the context of existing knowledge in the literature and a review of previous work on epilepsy in Mali. This study will significantly contribute to the ongoing debate on how and when to use plasma dosage of AEDs in clinical care. This pilot pharmacokinetic study was our first step towards future pharmacogenomic studies for personalized AED treatment in Mali, West Africa.

Epilepsy is a chronic disease with a severity ranging from benign idiopathic condition to extremely severe form due to encephalopathies. ${ }^{1,2}$ People living with epilepsy may experience spontaneous resolution of their condition in $70 \%$ of cases, but $20-30 \%$ will have resistant epilepsy over time. ${ }^{3}$ Epilepsy affects 50 million people worldwide and $5-10 \%$ of the total population in the United States of America (USA) and Europe. ${ }^{4}$ Sub-Saharan Africa hosts $80 \%$ of the world epilepsy population with a prevalence of $15.4 \%$ and a frequency of 50-105 cases each year. ${ }^{5}$ However, the global burden of epilepsy has been difficult to estimate in Africa due in part to the heterogeneity of the reports. ${ }^{6}$ Uncontrolled seizures can seriously impact the socio-professional and family life of patients. ${ }^{3}$ Care in epilepsy usually requires AEDs. The efficiency of AED treatment depends on the etiology and clinical forms of epilepsy as well as the adherence of patients to the treatment. ${ }^{7,8}$ The overall goal of AED treatment is to prevent further seizures, avoid adverse effects, and enable patients to be active with improved quality of live. ${ }^{8,9}$ This requires an appropriate choice and posology (efficient $\mathrm{mg} / \mathrm{kg} /$ day) of AEDs coupled to a good treatment monitoring plan. ${ }^{10}$

Monitoring of AED treatment follows different standards worldwide. The best medical practice requires that an ambulatory patient starts with monotherapy (efficient $\mathrm{mg} / \mathrm{kg} / \mathrm{day}$ ). Bi-therapy or add-on therapy should be rationally chosen. In the USA and Europe, sequential monitoring of AED plasma level is recommended especially for clinical toxicity, clinical response, and switching or adding another AED to the treatment. ${ }^{11}$ In Sub-Saharan Africa, best clinical practices in epilepsy widely vary across countries. As a trend, in low income countries, about $60 \%$ of people living with epilepsy receive no antiepileptic treatment due largely to economic and social reasons, ${ }^{12}$ and a much higher pro- portion have no access to electroencephalogram (EEG) and AED plasma dosage tests. In middle income countries (Tunisia and Kenya), continuous EEG monitoring and sequential AED plasma level are only for pediatric or non-traumatic comatose patients. ${ }^{13,14}$ In high income African countries (South Africa and Egypt), clinical application of epilepsy genetics in pediatric or refractory patients has been considered. 15,16 $^{-16}$

In Mali, one of the poorest countries in the world, the prevalence of epilepsy has been estimated at $14.6-15.6 \% .{ }^{17}$ Generalized seizures are well-known and recognized by many health professionals across the country. ${ }^{17}$ Therefore, the socio-cultural context deeply affects the beliefs and perceptions of the disease, and affected women of childbearing age are the most stigmatized. ${ }^{9}$ Epilepsy screening, diagnosis and treatment are widely disparate between rural and urban areas. In the capital city Bamako, people living with epilepsy are referred from public and private health facilities to neurologists at the two main university teaching hospitals where neurologists, psychiatrist and child neurologists can easily be found. ${ }^{18}$ Here, patients benefit from a good medical history taking and physical examination, EEG and second line AEDs. Outside the capital city, people living with epilepsy are diagnosed and treated by medical doctors or general practitioners (GPs) as well as trained nurses. In 2018, the non-governmental organization Santé Sud trained 18 GPs from rural Mali to diagnose and treat mainly convulsive epilepsy. The knowledge gap in epilepsy in general physicians can be traced back to their formal training at the medical school. ${ }^{19}$ For example, up to date, plasma AED level monitoring is part of the follow up of the AED treatment to either monitor side effects or change/add AEDs, but not yet done due to financial constraints.

Epilepsy treatment gap is defined as the proportion of people who should normally be treated, but are not receiving any treatment. This gap ranges from $75 \%$ to $90 \%$ in low income African countries. ${ }^{20}$ Disparity in epilepsy diagnostic and treatment is obvious between rural and urban settings in Mali. ${ }^{17}$ Therefore, the responsibility falls on the shoulders of the scientific community in general and the Malian league against epilepsy in particular to coordinate the effort in addressing epilepsy care as a public health problem in Mali. We wanted to estimate the epilepsy diagnostic and drug treatment gap between rural and urban areas in Mali. How could such a treatment gap be minimized or bridged as much as possible through evidence-based practices? To answer these questions, we hypothesized that implementing two different questionnaires (a well-designed and easy-to use sequential epilepsy treatment follow up and the McGill quality of life), and eventually, plasma level of AEDs as part of the 
AED treatment could lead to a better quality of life in people living with epilepsy in rural Mali. In this study, we sought to highlight the epilepsy treatment gap between rural and urban settings and to raise awareness for changing the mindsets on AED treatment in Mali.

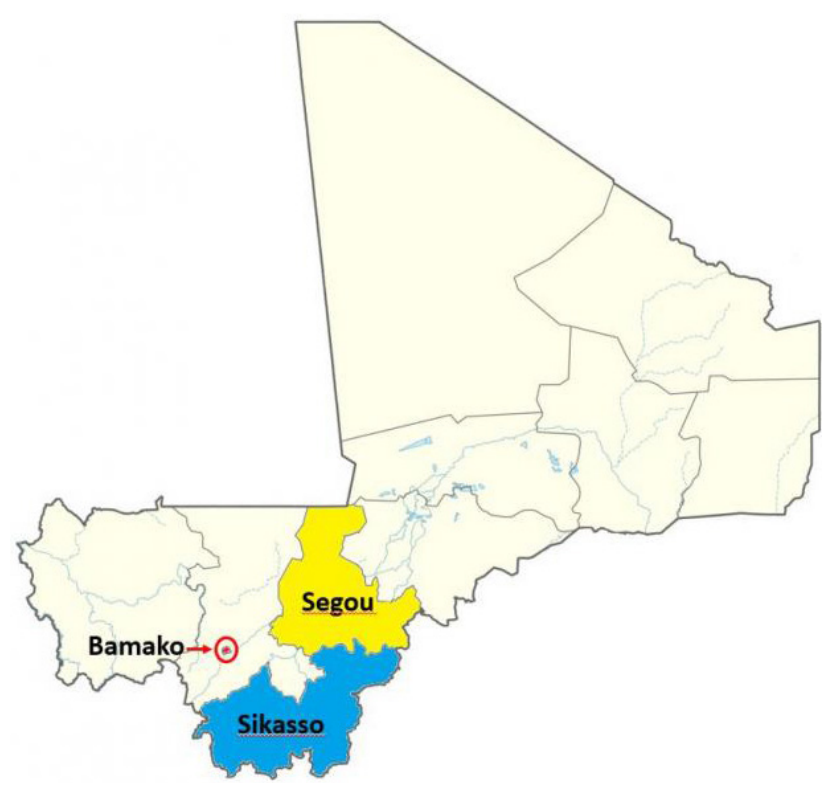

Figure 1. Map of Mali showing Segou, Sikasso and Bamako highlighted in yellow, blue, and red respectively.

\section{Methods}

\section{Patient recruitment and data collection}

We conducted a prospective pilot study from September 2016 to May 2019. Patients received free first line AEDs (phenobarbital, valproic acid, and carbamazepine) for 6 months, prescribed by a neurologist, psychiatrist or a pediatrician. Our study sites included Bamako, the capital city, representing the urban cities and Segou, a rural site (Fig. 1). We choose our two study sites because all the neurologists and most general physicians with interest in epilepsy worked at the three main university teaching hospitals in the capital city, Bamako. Epilepsy diagnostic and management should therefore be the best possible in the country. Rural Segou is renowned for one of the highest rates of consanguineous and even endogamous marriage and a relatively high likelihood for marriage between people living with epilepsy.

At our urban study site, from September 2016 to August 2017, we enrolled 30 autistic children aged 3-14 years old, who were treated for focal onset epilepsy with impaired awareness. At inclusion, patients underwent ophthalmologic and ear, nose and throat examination, EEG brain computed tomography (CT) scan and received AEDs for 6 months. Plasma dosage of AEDs was carried out at first month $M 1(n=30)$ and at three months M3 $(n=6)$ and patients were followed up till November 2018. EEG recordings were independently reviewed by a neuro-pediatrician and a neurologist. No patient was given phenobarbital in Bamako due to the suspicion of ASD as a co-morbidity of epilepsy and

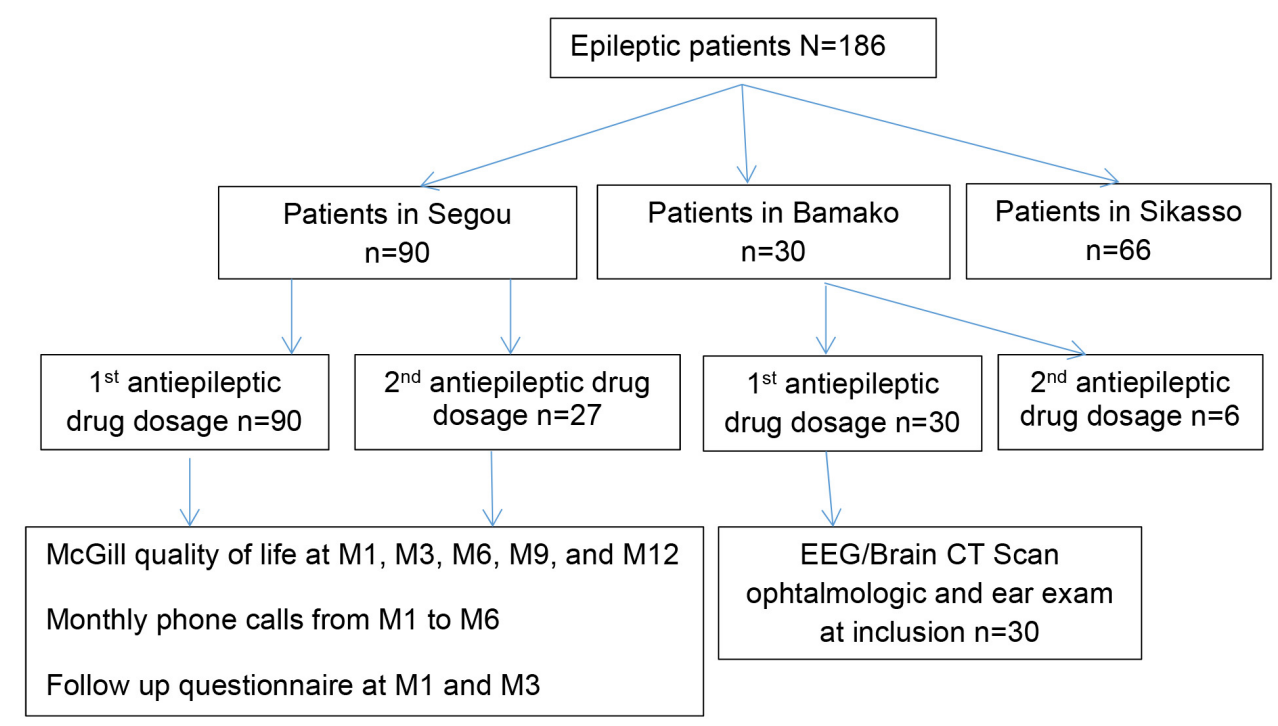

Figure 2. Flow chart of study participant recruitment during the study. 
the younger age of our study participants. It is well-known that phenobarbital has been associated with hyperactivity and low appreciation rate when prescribed to young children with ASD. ${ }^{21}$

At our rural study site in Segou, from October 2017 to November 2018, we recruited and followed up 90 patients with generalized epilepsy at the local community health center. Either frequency and severity or the Quality of Life in Epilepsy-31 or the WHO quality of life-BREF scale has been used separately to monitor the effectiveness of epilepsy treatment. ${ }^{22-24}$ We chose to use a follow up questionnaire and the McGill quality of life in our study. First, we administered to each patient with our follow up questionnaire to inquire about the frequency, and duration of seizures at M1 and M3 as well as the monthly phone call for the occurrence of side effects from the initiation of the treatment. We also administered the McGill quality of life questionnaire to inquire about the global quality of life of patients at the following time points (M1, M3, M6, M9, and M12). Epilepsy frequency was categorized before the treatment into $<60 /$ month and $\geq 60 /$ month and after the initiation of the treatment $<1 /$ month and $\geq 1 /$ month. Epilepsy duration was categorized before the treatment into $<5$ minutes and $\geq 5$ minutes and $<1$ minute and $\geq 1$ minute after the initiation of the treatment. Based on the patient's subjective assessment of the most severe seizure in the last month before the administration of the study questionnaire, epilepsy intensity was grouped into three categories before and after the initiation of the treatment as followed: mild (not assessed due to no seizure to less severe than a regular seizure before treatment), moderate (no change in the perceived seizure severity even with efficient $\mathrm{mg} / \mathrm{kg}$ body weight antiepileptic drug treatment), and severe (the patient felt the initiation of the antiepileptic drug worsened his/her seizure). AED plasma level were determined in patients at M1 $(n=90)$ and at M3 ( $n=27)$ (Fig. 2).

\section{Plasma sample collection and analysis}

At our rural study site, after community consent and individual informed consent, we took two $4 \mathrm{~mL}$ of blood samples from each enrolled patient in the morning. Within 1 hour, we centrifuged the whole blood to collect plasma samples in two 1.5-mL Eppendorf tubes to be stored immediately at $4^{\circ} \mathrm{C}$. Within 72 hours, plasma levels of AEDs were determined using an immune-enzymatic method at the Algi laboratory or a chromatography-based approach at the Rodolphe Merieux laboratory in Bamako. We received AED plasma levels with the range of normal values (therapeutic range in mono- or bi-therapy) by age and sex, which we easily categorized as low, normal or high AED plasmatic levels.

\section{DNA extraction}

DNA was extracted from the buffy coat using the Gentra kit Cat\#158545 for future pharmacogenomic studies.

\section{Identification of cytochrome P450 isoforms for AED pharmacogenomics studies}

We searched dbSNP database to identify isoforms of cytochrome P450 implicated in the metabolism of first line AEDs (phenobarbital, carbamazepine, and valproic acid) (Table 1).

Table 1. Identification of cytochrome P450 candidate genes involved in the metabolism of antiepileptic drugs for future pharmacogenomic studies in Mali

\begin{tabular}{lcccl}
\hline CYP gene family & Sub-family & Location & Liver RKPM & \multicolumn{1}{c}{ Metabolites and type of metabolism } \\
\hline CYP1 & CYP1A1 & $15 \mathrm{q} 24.1$ & 18.0 & Phenobarbital (I) \\
& CYP1A2 & $15 \mathrm{q} 24.1$ & 100.8 & Phenobarbital (I) \\
CYP2 & $19 \mathrm{q} 13.2$ & 542.0 & Phenobarbital (I) \\
& CYP2A6 & $19 \mathrm{q} 13.2$ & $124 \pm 28.46$ & Phenobarbital (I) \\
& CYP2C8 & $10 \mathrm{q} 23.33$ & 350.3 & Phenobarbital (I) \\
& CYP2C9 & $10 \mathrm{q} 23.33$ & 331.8 & Phenobarbital (I), Valproic acid (S), Carbamazepine (S) \\
& CYP2C19 & $10 \mathrm{q} 23.33$ & 80.1 & Phenobarbital (I) \\
& CYP2D6 & $22 \mathrm{q} 13.2$ & 40.1 & Phenobarbital (I) \\
& CYP2E1 & $10 \mathrm{q} 26.3$ & 2134.3 & Phenobarbital (I) \\
CYP3 & $7 \mathrm{q} 22.1$ & 476.5 & Phenobarbital (I), Valproic acid (S) \\
& CYP3A4 & $7 \mathrm{q} 22.1$ & 28.49 & Phenobarbital (I), Carbamazepine (S)
\end{tabular}

RKPM, read per kilobase per million; I, enzyme inducer; S, enzyme subtract. 
Table 2. Comparison of frequency and duration of epileptic crises before and during antiepileptic drug treatment in our cohort

\begin{tabular}{lcc}
\hline \multirow{2}{*}{ Seizure } & \multicolumn{2}{c}{ Antiepileptic drug treatment } \\
\cline { 2 - 3 } & $\begin{array}{c}\text { Before treatment } \\
(n=90)\end{array}$ & $\begin{array}{c}\text { During treatment } \\
(\mathrm{n}=90)\end{array}$ \\
\hline Frequency & & \\
$<1 /$ month & 0 & 24 \\
$\geq 1$ /month & 0 & 66 \\
$<60 /$ month & 79 & 0 \\
$\geq 60 /$ month & 11 & 0 \\
Duration & & \\
$<5$ minutes & 21 & 0 \\
$\geq 5$ minutes & 69 & 0 \\
$<1$ minute & 0 & 15 \\
$\geq 1$ minute & 0 & 75 \\
Intensity or severity & & 84 \\
Mild* & 40 & 4 \\
Moderate & 30 & 2 \\
Severe $^{\ddagger}$ & 20 & \\
\hline
\end{tabular}

${ }^{*} \chi^{2}=53,018 ; p<0.000001$.

${ }^{*}$ Fisher exact test $p<0.00001$.

${ }^{\ddagger}$ Fisher exact test $p<0.000001$.

\section{Ethical considerations}

Our study protocol, consent forms and study questionnaire were approved in 2016 by the Institutional Review Board (IRB) at the Faculty of Medicine and Odonto-Stomatology (FMOS). Despite the community consent in rural settings, we sought and obtained informed individual consents and assents. Each participant was compensated at an IRB-approved rate and transport fees were reimbursed. Only the medical student, her mentor and the data analyzer had access to the database. Information was coded and the data analyzer did not access the code keys. To maximize the benefits and minimize the harm, and also to ensure adherence to treatment, we provided patients with a 6-month supply of AEDs. Plasmatic dosages were determined free of charge for patients.

\section{Statistical analysis}

We used SPSS version 25 (IBM Corp, Armonk, NY, USA) to generate frequency tables and compare data at different time points using chi square, Fisher exact test, or ANOVA. $p$-values less than 0.05 were considered statistically significant.

Table 3. Sequential dosage of plasma level of antiepileptic drugs in patients with epilepsy in our cohort

\begin{tabular}{|c|c|c|c|c|}
\hline \multirow{3}{*}{ Antiepileptic drug } & \multicolumn{4}{|c|}{ Plasmatic dosage during treatment } \\
\hline & \multicolumn{2}{|c|}{ Rural study site* } & \multicolumn{2}{|c|}{ Urban study site } \\
\hline & At 1 month & At 3 months & At 1 month & At 3 months \\
\hline \multicolumn{5}{|l|}{ Phenobarbital } \\
\hline Low & $29(32.2)$ & $8(29.6)$ & $0(0.0)$ & $0(0.0)$ \\
\hline Normal & $30(33.3)$ & $13(48.2)$ & $0(0.0)$ & $0(0.0)$ \\
\hline High & $7(7.8)$ & $3(11.1)$ & $0(0.0)$ & $0(0.0)$ \\
\hline Sub-total 1 & $66(73.3)$ & $24(88.9)$ & $0(0.0)$ & $0(0.0)$ \\
\hline \multicolumn{5}{|l|}{ Carbamazepine } \\
\hline Low & $5(5.6)$ & $1(3.7)$ & $18(60.0)$ & $2(33.3)$ \\
\hline Normal & $12(13.3)$ & $1(3.7)$ & $10(33.3)$ & $4(66.7)$ \\
\hline High & $0(0.0)$ & $0(0.0)$ & $2(6.7)$ & $0(0.0)$ \\
\hline Sub-total 2 & $17(18.9)$ & $2(7.4)$ & $30(100.0)$ & $6(100.0)$ \\
\hline \multicolumn{5}{|l|}{ Valproic acid } \\
\hline Low & $4(4.4)$ & $0(0.0)$ & $18(60.0)$ & $2(33.3)$ \\
\hline Normal & $3(3.3)$ & $1(3.7)$ & $0(0.0)$ & $4(66.7)$ \\
\hline High & $0(0.0)$ & $0(0.0)$ & $2(6.7)$ & $0(0.0)$ \\
\hline Sub-total 3 & $7(7.8)$ & $1(3.7)$ & $20(66.7)$ & $6(100.0)$ \\
\hline Total & $90(100.0)$ & $27(100.0)$ & $30(100.0)$ & $6(100.0)$ \\
\hline
\end{tabular}

Values are presented as number (\%).

*One-way ANOVA to compare plasmatic levels of antiepileptic drugs at M1 and M3 in 27 patients at our rural study site $F(4,9)=21,0 . p=0.0001$. 


\section{Results}

In our cohort, the sex-ratio was 1.8 in favor of males. At the urban study site, patients ( $n=30$ ) were 10 years-old on average with the extremes of 3 and 14 years-old. All patients were suspected with autism spectrum disorder (ASD) with focal onset epilepsy. None was prescribed phenobarbital. In total, 66.67\% patients (20/30) were on bi-therapy (carbamazepine and valproic acid) at inclusion. Patients had good adherence to their treatment (100\%) by the end of the follow up. Only 20\% (6/30) on bi-therapy did both plasma AED dosages at $\mathrm{M} 1$ and $\mathrm{M} 3$ and they were still taking their medications by the end of the follow up in November 2018 (27 months in total). Thus, 80\% (24/30) were off medication. EEG abnormalities supporting the clinical diagnostic of epilepsy were found in 55.8\% (17/30). Brain CT scan was normal in all 30 patients.

At our rural study site, the mean age of patients ( $n=90$ ) was 17.7 \pm 9.15 years old. The most represented age range was $16-30$ years old with $50 \%$ (45/90). Patients clinically diagnosed with generalized epilepsy were treated with either phenobarbital or carbamazepine or valproid acid in monotherapy. The adherence rate of the AED treatment was 79\% (71/90) after the first 6 months. The co-morbidity of epilepsy and ASD was found in 8.9\% (8/90).

At our rural study site, we found at 3 months' time point during the antiepileptic treatment that seizures were less frequent $(<1 /$ month) in $26.7 \%$ (24/90), and shorter than 1 minute in 16.7\% (15/90) (Table 2).

Table 4. Occurrence of side effects of antiepileptic drugs in patients with epilepsy in our cohort

\begin{tabular}{lccc}
\hline \multirow{2}{*}{ Antiepileptic drug } & \multicolumn{3}{c}{ Side effects during treatment } \\
\cline { 2 - 4 } & Present & Absent & Total \\
\hline Phenobarbital & $11(12.2)$ & $55(61.1)$ & $66(73.3)$ \\
Carbamazepine & $0(0.0)$ & $18(20.0)$ & $18(20.0)$ \\
Valproic acid & $1(1.1)$ & $5(5.6)$ & $6(6.7)$ \\
Total & $12(13.3)$ & $78(86.7)$ & $90(100.0)$ \\
\hline
\end{tabular}

Values are presented as number (\%).
At our urban study site, $66.7 \%$ (20/30) of our study participants were on bi-therapy (carbamazepine and valproid acid) and $60 \%$ (18/30) on bi-therapy had low plasma level for each individual AED. At our rural study site, patients were mostly on monotherapy and AED levels were normal in 50\% (45/90), low in 42.2\% (38/90) and high in $7.8 \%(8 / 90)$ at 1 month of treatment. At 3 months' time point, AED level was normal in 55.6\% (15/27), low in 33.3\% (9/27) and high in $11.1 \%(3 / 27)$. Plasma level of AEDs were significantly different at $\mathrm{M} 1$ and $\mathrm{M} 3$ for 27 patients who were tested twice $p<0.0001$. At our urban study site, patients were mostly on bi-therapy and AED levels were normal in 33.3\% (10/30), low in 60\% $(18 / 90)$ and high in $6.7 \%(2 / 30)$ at 1 month of treatment. Eight patients at M1 had high plasma level of AEDs (Table 3).

At our rural study site, $13.3 \%$ (12/90) had side effects of AEDs at M1 with phenobarbital in 12.2\% (11/90) (Table 4).

Patients estimated their global quality of life as "good or excellent from $95.6 \%(86 / 90)$ at inclusion to $100 \%(90 / 90)$ at 12 months' time points. No correlation was made between the frequency and severity of epilepsy and the quality of life of patients in our cohort (Table 5).

\section{Discussion}

Our findings suggested an overall improved quality of life of people living with epilepsy in both rural and urban areas through a close monitoring using our study questionnaires (easy-to use sequential epilepsy treatment follow up and the McGill quality of life). Such clinical improvement in epilepsy could be better felt using the McGill quality of life over 12 months every 3 months from inclusion.

After 12 months of follow up, all enrolled patients or their care takers/parents from our rural study site estimated their global quality of life to be good or excellent. One underlying reason for such improved quality of life in people living with epilepsy was the readily availability of free AEDs for the first 6 months of treatment. A good observance of the AED treatment is essential to control epilepsy. We

Table 5. Sequential assessment of the McGill Quality of life of epileptic patients in our cohort over 12 months

\begin{tabular}{lccccccc}
\hline \multirow{2}{*}{ McGill quality of life } & & \multicolumn{3}{c}{ Assessment of global quality of life during antiepileptic treatment $(\mathrm{n}=90)$} \\
\cline { 1 - 4 } \cline { 5 - 8 } Score & Interpretation & & Month 1 & Month 3 & Month 6 & Month 9 & Month 12 \\
\hline $0-1$ & Very poor & & $2(2.2)$ & $1(1.1)$ & $0(0.0)$ & $0(0.0)$ & $0(0.0)$ \\
$2-3$ & Poor & & $2(2.2)$ & $3(3.3)$ & $3(3.3)$ & $1(1.1)$ & $0(0.0)$ \\
$4-10$ & Good/excellent & & $86(95.6)$ & $86(95.6)$ & $87(96.7)$ & $89(98.9)$ & $90(100.0)$ \\
\hline
\end{tabular}

Values are presented as number (\%). 
made sure that AEDs were available and affordable to patients at their local community health center. Another reason for such improved quality of life in people living with epilepsy was the regular doctor visits every 3 months. Overall, our rationale of developing an epilepsy follow up questionnaire based on frequency, severity, and duration of the seizures along the McGill quality of life was to foster a solid physician-patient relationship and regular doctor visits for a better outcome of the treatment. Poor follow-up has been reported in a large multinational study in Europe in which approximately 50\% of the people living with epilepsy had not seen their specialist in the year preceding the survey. ${ }^{25}$

An optimal epilepsy treatment plan is partly based on an accurate diagnosis of the patient's seizure type(s), an objective measure of the intensity and frequency of the seizures, and the awareness of the side effects of available AEDs. ${ }^{26}$ At our rural study site, we found at 3 months' time point during the antiepileptic treatment that seizures were less frequent ( $<1 /$ month) in 26.7\% (24/90), and shorter than 1 minute in 16.7\% (15/90) (Table 2). Even though, in people living with epilepsy, seizure severity and frequency have a limited negative impact mostly on the social aspects of the quality of life, ${ }^{27}$ epilepsy frequency not severity is the main factor, which determines in practice how stigma and overall quality of health are perceived. ${ }^{28}$ Our follow up questionnaire could be useful to physicians to monitor epilepsy treatment at rural community health centers in Mali.

From our rural and urban study sites, plasma level of AEDs was significantly different at $\mathrm{M} 1$ and $\mathrm{M} 3$ in 27 patients who were tested twice $(p<0.0001)$. Only half of our study participants had a normal plasma level of AED at the first test (Table 3). As long as patients were seizure free and experienced no serious side effects, low or high plasma levels of AEDs were concerning. Physicians and patients expect that optimal plasma level directly correlate with the clinical efficacy of the treatment. Total plasma AED level is just an indication of the total quantity of medication in the blood, but only the free proportion of the medication (not bound to a protein) is active. Nevertheless, prescription of AEDs solely based on body weight or efficient $\mathrm{mg} / \mathrm{kg} /$ day by age and sex as suggested by the drug manufacturer may not often guarantee such expectation.

Our study participants received a monotherapy at our rural study site and polytherapy in Bamako. Polytherapy usually comes with suboptimal $\mathrm{mg} / \mathrm{kg} /$ day dose for each individual medication due caution for synergic mechanism of action of AED. ${ }^{29}$ Valproic acid and carbamazepine were always combined to treat patients in Bamako. This could be the case when people living with epilepsy either consulted more than one healthcare provider or less likely the same specialist. In the other hand, epilepsy associated with ASD and especially focal onset epilepsy is more prone to become resistant to fist-line AEDs. Physicians then needs more than one AED to control the seizures. Knowing that anticonvulsant polytherapy has widely and traditionally been used in the treatment of epilepsy without any real added value to monotherapy, ${ }_{1}^{29}$ monotherapy with phenobarbital was mainly prescribed in rural Mali. The affordability of phenobarbital by our study participants after our follow up period was also a key determining factor for monotherapy with phenobarbital.

The disparity between rural and urban Mali in terms of healthcare services and AEDs available to people living with epilepsy was obvious. For instance, before our study, phenobarbital used to be discontinued at the local community health center in Segou. In our rural study site, epilepsy was fairly common and the most frequently represented age range was $16-30$ years old with $50 \%$ (45/90). This result confirmed the highest prevalence of epilepsy in the first two decades of life (70.8\%) in Libya $(n=568) .{ }^{30}$ Active convulsive epilepsy usually starts in childhood ${ }^{31}$ and it peaks in the age group 20-29 years old with a prevalence of 11.5/1000. A high prevalence of epilepsy, especially in young adults, has important negative consequences for both the workforce and the community in Sub-Sahara Africa. ${ }^{31}$ Especially, at our rural study site, parents/caregivers of people living with epilepsy were farmers, livestock breeders or fishmen. In addition, moderate and severe epilepsy may not be compatible with independence or autonomy for the patients most of the time. Taken together, parents may be required to watch closely after their children living with epilepsy. At least, an improved quality of life in people living with epilepsy may therefore free up their caregivers to take care to their daily activities. Our findings should prompt decision makers to issue health policy to trained health professionals in epilepsy and to make essential antiepileptic medicines and EEG available to the district health center in each province of the country.

We have shown an improved quality of life with a close monitoring of AED treatment in our rural study site. How much of this improved quality of life translated into patients' autonomy or independence to relieve the people living with epilepsy, their families and their community from the burden of epilepsy? We still don't know yet. In the future, a large and well-designed epilepsy prevalence study will help reassess the cartography of epilepsy across the country. Such study could be combined with genetic and pharmacogenomic studies on epilepsy in rural Mali. To anticipate, genetic testing to predict adverse effects of AEDs will result in a more efficacious and safer AED treatment. ${ }^{32}$ For 
that purpose, the plasmatic level of AEDs will even more relevant to characterize clinically study participants. Pharmacogenomic studies on classic AEDs may focus on cytochrome P450 genes (CYP2B6, CYP2C9, and CYP3A4) (Table 1). To ensure the quality of life of people living with epilepsy, physicians will wonder in years from now about "Which drug?" and "Which dose?" for my patient living with epilepsy. ${ }^{32,33}$ Plasma dosage of AEDs may not be commonly used in clinical practice, but it will be more relevant for pharmacogenomic studies and personalized medicine.

Our study had few limitations. First, our initial study design was to find perfectly matched controls (age, sex, clinical diagnostic, and AED treatment) in rural areas for the patients recruited at the urban study site. We failed to follow the study participants concomitantly from both study sites. Alternatively, we stuck to the reasonably appropriate monitoring that could be implemented routinely on a case-to-case basis in both rural and urban settings. Second, we did not compare data from rural and urban study sites because our patient population was not representative of pediatric epilepsy in the urban setting and it was completely different from our patient population in the rural setting (age group, type of epilepsy, and mostly used AED). The most comparable data was the plasma level of AEDS, but neither the treatment regimen (mono- vs. bi-therapy) nor the age range of patients were similar. Such comparison would be almost erroneous and clinically meaningless. Despite the limitations, this pilot study yielded useful preliminary data to highlight the disparities in epilepsy diagnostic and treatment between rural and urban areas and the potential to improve the monitoring of epilepsy treatment in both settings in Mali. Our data allow to raise questioning and wonder about the epilepsy treatment gap among stakeholders and health policy makers in Mali. Without strong evidence to drive policy change, the epilepsy diagnosis and treatment gap will persist for long time in developing countries. ${ }^{20}$

Our data showed that the quality of life of people living with epilepsy could be improved using a close monitoring of AED treatment in the rural setting in Mali. Epileptic drug treatment was disparate between rural and urban setting in Mali. To close the equity gap in epilepsy diagnosis and treatment in Mali, health professionals in the rural areas should be trained in epilepsy and mindsets about plasmatic dosage of AEDs in the urban setting to improve current standard of epilepsy diagnosis and treatment should be also changed. The scientific community of epilepsy should come together in a concerted effort to tackle these challenges. With a continuous and well-coordinated epilepsy research collaboration and public engagement, per- sonalized AED prescription is potentially feasible in Mali in the future.

\section{Acknowledgements}

We acknowledged the physicians in chief at our rural study site in the community health centers (Dr. Noumakan Camara and Dr. Salikou Sanogo) for the mobilization of local guides and study participants, all our study participants for the time and effort, and Dr. Brehima Traore from the biomedical lab Rodolphe Merieux in Bamako, Mali for his collaboration during this study.

Dr. Modibo Sangare, MD, PhD was supported by a postdoctoral fellowship from a DELTAS Africa grant (DEL-15-007: Awandare). The DELTAS Africa Initiative is an independent funding scheme of the African Academy of Sciences (AAS)'s Alliance for Accelerating Excellence in Science in Africa (AESA) and supported by the New Partnership for Africa's Development Planning and Coordinating Agency (NEPAD Agency) with funding from the Wellcome Trust (107755/Z/15/Z: Awandare) and the UK government. The views expressed in this publication are those of the author(s) and not necessarily those of AAS, NEPAD Agency, Wellcome Trust or the UK government.

Dr. Modibo Sangare was also a grantee of the University of Sciences, Techniques and Technologies of Bamako, Ministry of Higher Education and Scientific Research of Mali.

\section{Conflict of Interest}

The authors declare that they have no conflicts of interest.

\section{References}

1. Ville D. What's about new treatments in children epilepsy in 2010? Arch Pediatr 2010;17:688-90.

2. Sabaz M, Cairns DR, Lawson JA, Nheu N, Bleasel AF, Bye AM. Validation of a new quality of life measure for children with epilepsy. Epilepsia 2000;41:765-74.

3. Ville D. L'épilepsie de l'enfant. Contraste 2013;38:37-57.

4. Leonardi M, Ustun TB. The global burden of epilepsy. Epilepsia 2002;43 Suppl 6:21-5.

5. Preux PM, Druet-Cabanac M. Epidemiology and aetiology of epilepsy in Sub-Saharan Africa. Lancet Neurol 2005;4:21-31.

6. Ngugi AK, Bottomley C, Kleinschmidt I, Sander JW, Newton CR. Estimation of the burden of active and life-time epilepsy: a meta-analytic approach. Epilepsia 2010;51:883-90.

7. Beghi E. Treating epilepsy across its different stages. Ther Adv Neurol Disord 2010;3:85-92.

8. Goldenberg MM. Overview of drugs used for epilepsy and seizures: etiol- 
ogy, diagnosis, and treatment. P T 2010;35:392-415.

9. Arborio $S$, Dozon JP. Sociocultural dimension of epilepsy (kirikirimasien) in a Bambara rural area (Mali). Bull Soc Path Exot 2000;93:241-6.

10. St Louis EK. Monitoring antiepileptic drugs: a level-headed approach. Curr Neuropharmacol 2009;7:115-9.

11. Patsalos PN, Berry DJ, Bourgeois BF, et al. Antiepileptic drugs--best practice guidelines for therapeutic drug monitoring: a position paper by the subcommission on therapeutic drug monitoring, ILAE Commission on Therapeutic Strategies. Epilepsia 2008;49:1239-76.

12. Ba-Diop $A$, Marin $B$, Druet-Cabanac $M$, Ngoungou EB, Newton $C R$, Preux PM. Epidemiology, causes, and treatment of epilepsy in sub-Saharan Africa. Lancet Neurol 2014;13:1029-44.

13. Charfi R, Lakhal M, Klouz A, Trabelsi S, Salouage I. Therapeutic drug monitoring of valproic acid in children: a prospective study of the effect of the compliance and the economic level on the trough plasmatic concentrations and epileptic seizures. Therapie 2015;70:415-24.

14. Gwer $S$, Idro R, Fegan $G$, et al. Continuous EEG monitoring in Kenyan children with non-traumatic coma. Arch Dis Child 2012;97:343-9.

15. Ebid AH, Ahmed MM, Mohammed SA. Therapeutic drug monitoring and clinical outcomes in epileptic Egyptian patients: a gene polymorphism perspective study. Ther Drug Monit 2007;29:305-12.

16. Esterhuizen Al, Carvill GL, Ramesar RS, et al. Clinical application of epilepsy genetics in Africa: is now the time? Front Neurol 2018;9:276.

17. Jaffré $Y$, Humbert $A$, Arborio $S$, Farnarier $G$. Etude anthropologique de I'épilepsie au Mali - I. Présentation générale. Epilepsies 2001;13:29-32.

18. Traoré M, Tahny $R$, Sacko M. Prévalence de l'épilepsie chez les enfants de 3 à 15 ans dans 2 communes du district de Bamako. Rev Neurol 2000;156(Suppl 1):1S18.

19. Maiga $Y$, Nguyen The Tich $S$, Dicko $F$, et al. Interest of a continuous EEG monitoring (CEEG) in a neonatology intensive care unit in Nantes (France). AJNS 2009;28:49-54.

20. Ekeh BC, Ekrikpo UE. The knowledge, attitude, and perception towards epilepsy amongst medical students in Uyo, Southern Nigeria. Adv Med 2015;2015:876135.

21. Kvalsund MP, Birbeck GL. Epilepsy care challenges in developing countries. Curr Opin Neurol 2012;25:179-86.

22. Frye RE, Rossignol D, Casanova MF, et al. A review of traditional and novel treatments for seizures in autism spectrum disorder: findings from a systematic review and expert panel. Front Public Health 2013;1:31.

23. Szaflarski JP, Bebin EM, Cutter $G$, et al. Cannabidiol improves frequency and severity of seizures and reduces adverse events in an open-label add-on prospective study. Epilepsy Behav 2018;87:131-6.

24. Pimpalkhute SA, Bajait CS, Dakhale GN, Sontakke SD, Jaiswal KM, Kinge P. Assessment of quality of life in epilepsy patients receiving anti-epileptic drugs in a tertiary care teaching hospital. Indian J Pharmaco/ 2015;47: 551-4.

25. Lotfinia M, Maloumeh EN, Asaadi S, Omidbeigi M, Sharifi G, Asadi B. Health-related quality of life after epilepsy surgery: a prospective, controlled follow-up on the Iranian population. Sci Rep 2019;9:7875.

26. Groenewegen A, Tofighy A, Rywlin P, Steinhoff BJ, Dedeken P. Measures for improving treatment outcomes for patients with epilepsy--results from a large multinational patient-physician survey. Epilepsy Behav 2014;34:58-67.

27. Schachter SC. Determining when to stop antiepileptic drug treatment. Curr Opin Neurol 2018;31:211-5.

28. Viteva El. Seizure frequency and severity: how really important are they for the quality of life of patients with refractory epilepsy. Ann Indian Acad Neurol 2014;17:35-42.

29. Eatock J, Baker GA. Managing patient adherence and quality of life in epilepsy. Neuropsychiatr Dis Treat 2007;3:117-31.

30. Sridharan R, Radhakrishnan K, Ashok PP, Mousa ME. Epidemiological and clinical study of epilepsy in Benghazi, Libya. Epilepsia 1986;27:60-5.

31. Paul A, Adeloye D, George-Carey R, Kolčić I, Grant L, Chan KY. An estimate of the prevalence of epilepsy in Sub-Saharan Africa: a systematic analysis. J Glob Health 2012;2:020405.

32. Depondt C. Pharmacogenetics in epilepsy treatment: sense or nonsense? Per Med 2008;5:123-31.

33. Dlugos DJ, Buono RJ, Ferraro TN. Defining the clinical role of pharmacogenetics in antiepileptic drug therapy. Pharmacogenomics / 2006;6: $357-9$. 